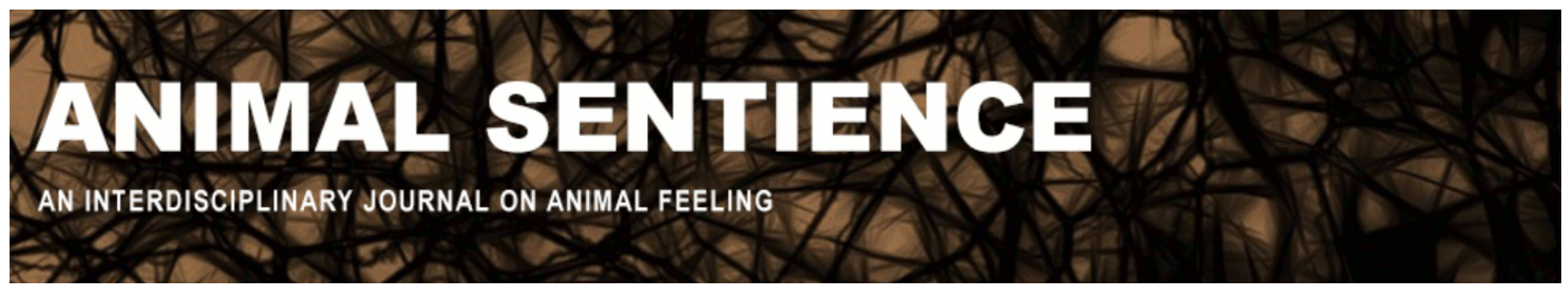

Prato Previde, Emanuela and Valsecchi, Paola (2018) What is it like to be a jealous dog?. Animal Sentience 22(16)

DOI: $10.51291 / 2377-7478.1348$

Date of submission: 2018-06-13

Date of acceptance: 2018-06-20

(c)

This article has appeared in the journal Animal

Sentience, a peer-reviewed journal on animal

cognition and feeling. It has been made open access,

free for all, by WellBeing International and deposited

in the WBI Studies Repository. For more information,

please contact

wbisr-info@wellbeingintl.org.

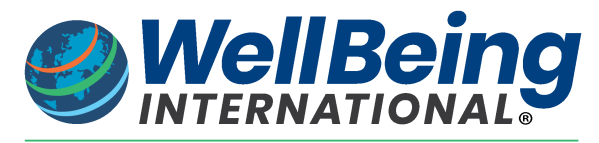

SOLUTIONS FOR PEOPLE, ANIMALS AND ENVIRONMENT 


\title{
What is it like to be a jealous dog?
}

Commentary on Cook et al. on Dog Jealousy

\section{Emanuela Prato Previde ${ }^{1}$ \& Paola Valsecchi ${ }^{2}$}

1. Università degli Studi di Milano, Dipartimento di Fisiopatologia Medico-Chirurgica e dei Trapianti

2. Università degli Studi di Parma, Dipartimento di Scienze Chimiche, della Vita e della

\section{Sostenibilità Ambientale}

\begin{abstract}
Jealousy is a good candidate for comparative studies due to its clear adaptive value in protecting social bonds and affective relationships. Dogs are suitable subjects for investigating the evolution of jealousy, thanks to their rather sophisticated socio-cognitive abilities - which in some cases parallel those reported for human infants - and thanks to their long-lasting relationship with humans. The work of Cook and colleagues (2018) addresses the issue of jealousy in dogs through the lens of neuroscience, examining the relationship between the amygdala and jealousy. Their experiment has a number of methodological flaws that prevent distinguishing jealousy from other internal states; it also lacks behavioral indicators that could help in this endeavor. Nevertheless, it is an admirable step towards a multidisciplinary approach to the investigation of non-basic emotions in nonhuman species.
\end{abstract}

Emanuela Prato Previde is associate professor of Psychology at the University of Milan; she has a PhD in Psychobiology. Her main research interests are: comparative psychology; comparative cognition; animal cognition; human-animal interactions and relationships; and the human-dog relationship in particular. She runs a small research lab at the University of Milan: the Canis sapiens Lab-Comparative Cognition \& Human-Animal Interaction. Website

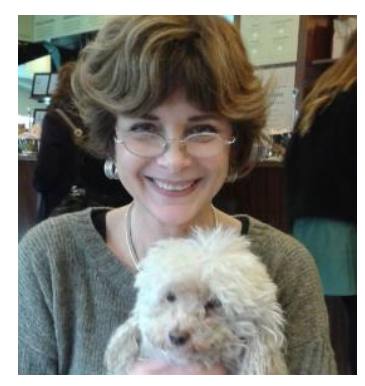

Paola Valsecchi is associate professor of Applied Ethology at the University of Parma; she has a $\mathrm{PhD}$ in Psychobiology. After many years spent studying social learning in small laboratory rodents, she is focused on intraspecific social behavior of free-ranging dogs, and on social cognition and welfare in the human-dog relationship. Website

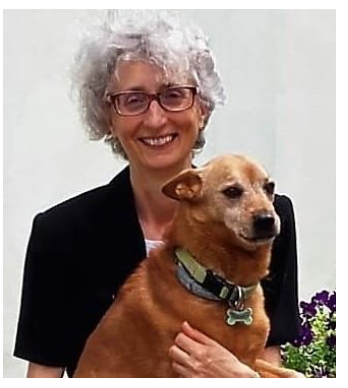

La jalousie est un mélange d'amour, de haine, d'avarice et de l'orgueil. (Alphonse Karr, 1839)

The growing body of research aimed at understanding emotions in non-human animals has a double relevance: improving the knowledge of the evolutionary path towards the complex emotional life of humans and gaining insight into animals' affective lives in order to guarantee their welfare and fulfill their needs in their relationships with humans. 
There is a general agreement that, because of their fundamental adaptive value, "basic" emotions such as fear and anger can be found in many vertebrate species. In contrast, evidence on the existence of "non-basic" or complex emotions such as jealousy, envy and guilt in non-human animals is still limited and provides mixed results (Horowitz, 2009; Steiner \& Redish, 2014; de Waal \& Preston, 2017; Kujala, 2017). Many researchers still assume that these emotions require elaborate cognitive abilities and emerge relatively late in human development; it is also believed that they imply self and interpersonal awareness, which is generally considered a unique human characteristic.

This perspective is changing, thanks to the contribution of human developmental studies and cross-species comparisons suggesting that some non-basic emotions play a fundamental role in regulating social life in animal species other than human (Draghi-Lorenz et al., 2001). This is the case for jealousy, which is considered a complex social emotion that involves an array of negative basic emotions (e.g., fear, anger, sadness). It arises in specific social contexts (e.g., sibling-parent, sexual, friendship) when one individual believes or perceives that a rival is threatening an affectionate relationship that is a source of material and psychological benefits (Hart, 2010; Dillon, 2013). In humans, this unpleasant emotion is generally accompanied by overt behaviors directed at restoring the relationship with a significant social partner as well as removing the social threat represented by the interloper.

Jealousy could have evolved as a strategy for protecting material and affective resources within the parent-offspring relationship and could be the most "basic" among complex social emotions. Indeed, experimental evidence indicates that cognitively immature children exhibit protest behaviors, negative vocalizations and proximity seeking when they lose maternal attention in favour of a potential rival (Hart et al., 2004). Autistic children also show jealous tendencies (Bauminger, 2010), although they exhibit deficiencies in expressions of pity, concern, guilt, and pride (Hobson, 2010). Panksepp (2010) theorized that jealousy does not necessarily arise from cortical processes that mediate social cognition, and Massar and colleagues (2009) showed that it could occur outside conscious awareness.

Studies on jealousy in non-human species are lacking; there are only a couple of behavioural studies on dogs (Canis familiaris), with contrasting results: Harris and Prouvost (2014) reported that dogs exhibited a pattern of behavior that appeared indicative of jealousy (e.g., aggressive behavior, pushing/touching the object/owner) when their owner manipulated a stuffed dog, but not other nonsocial objects (i.e., a jack-o-lantern and a book). Conversely, a study by our group (Prato-Previde et al., 2018) found no clear evidence that dogs considered a fake dog as a real social rival and reported no differentiated response in dogs when the owner (i.e., their attachment figure) and an unfamiliar person manipulated the faux dog compared to other nonsocial objects (i.e., a puppet and a book).

These pioneering works do not exclude the possibility that dogs exhibit a primordial form of jealousy, but they highlight the need for additional rigorous research. Hence the work of Cook and colleagues (2018) is really welcome, as it addresses the issue of jealousy in dogs from another perspective: functional brain imaging should help trace the roots of jealousy, by looking at the ancestral regions of the brain.

As already outlined in previous commentaries, however, this study presents a number of methodological limits (the lack of a control group, the choice of the fake dog, the choice of a food-based context rather than a merely affective one) that could be more or less easily corrected in future studies. We agree with other authors that Cook and colleagues overestimate their results in many respects: their dogs were not aggressive, according to the low values of CBARQ, and only 6 out 13 of them showed a positive differential amygdala 
activation (i.e., greater activation to the fake dog than to the bucket). Finally, in our opinion, there is too much emphasis on the aggressive component of the jealousy response: jealousy is a blended emotion made up of at least fear, anger, and sadness, apart from aggression; it can be expressed at a behavioral level through attention seeking, proximity, sustained visual attention and even avoidance.

Notwithstanding these limits, the present study represents a starting point for adjusting experimental protocols and producing new ideas to investigate a topic that is challenging because animals cannot give us verbal reports on their subjective experience.

\section{References}

Bauminger, N. (2010). Jealousy in autism spectrum disorders (ASD). In S.L. Hart \& M. Legerstee (Eds.), Handbook of jealousy: Theory, research, and multidisciplinary approaches, Wiley-Blackwell, pp. 267-292.

Cook, P., Prichard, A., Spivak, M., \& Berns, G.S. (2018). Jealousy in dogs? Evidence from brain imaging. Animal Sentience 22(1).

de Waal, F.B.M., \& Preston, S.D. (2017). Mammalian empathy: Behavioural manifestations and neural basis. Nature Reviews Neuroscience, 18, 498-509.

Dillon, L. (2013). Functional aspects of jealousy across the lifespan. Human Ethology Bulletin, 28, 1326.

Draghi-Lorenz, R., Reddy, V., \& Costall, A. (2001). Rethinking the development of "nonbasic" emotions: A critical review of existing theories. Developmental Review, 21, 263-304.

Harris, C.R. (2004). Evolution of jealousy. American Scientist, 92, 62-71.

Harris, C.R., \& Prouvost, C. (2014). Jealousy in dogs. PLoS One, 9(7), e94597.

Hart, S.L. (2010). The ontogenesis of jealousy in the first year of life: A theory of jealousy as a biologically-based dimension of temperament. In S.L. Hart \& M. Legerstee (Eds.), Handbook of jealousy: Theory, research, and multidisciplinary approaches. Wiley-Blackwell, pp. 57-82.

Hart, S.L., \& Carrington, H.A., Tronick, E.Z., \& Carrol, S.R. (2004). When infants lose exclusive maternal attention: is it jealousy? Infancy, 6, 57-78.

Hobson, R.P. (2010). Is jealousy a complex emotion? In S.L. Hart \& M. Legerstee (Eds.), Handbook of jealousy: Theory, research, and multidisciplinary approaches, Wiley-Blackwell, pp. 293-311.

Horowitz, A. (2009). Disambiguating the guilty look: Salient prompts to a familiar dog behaviour. Behavioural Processes, 81, 447-452.

Kujala, M.V. (2017). Canine emotions as seen through human social cognition. Animal Sentience, 14(1).

Massar, K., Buunk, A., \& Dechesne, M. (2009). Jealousy in the blink of an eye: Jealous reactions following subliminal exposure to rival characteristics. European Journal of Social Psychology, 39, 768-779.

Panksepp, J. (2010). The evolutionary sources of jealousy: Cross-species approaches to fundamental issues. In S.L. Hart \& M. Legerstee (Eds.), Handbook of jealousy: Theory, research, and multidisciplinary approaches. Malden: Wiley-Blackwell, pp. 101-120.

Prato-Previde, E., \& Nicotra, V., Pelosi, A., \& Valsecchi, P. (2018). Pet dogs' behavior when the owner and an unfamiliar person attend to a faux rival. PLOS ONE, 13(4), e0194577.

Steiner, A.P., \& Redish, A.D. (2014). Behavioral and neurophysiological correlates of regret in rat decision-making on a neuroeconomic task. Nature Neuroscience, 17(7), 995-1002. 


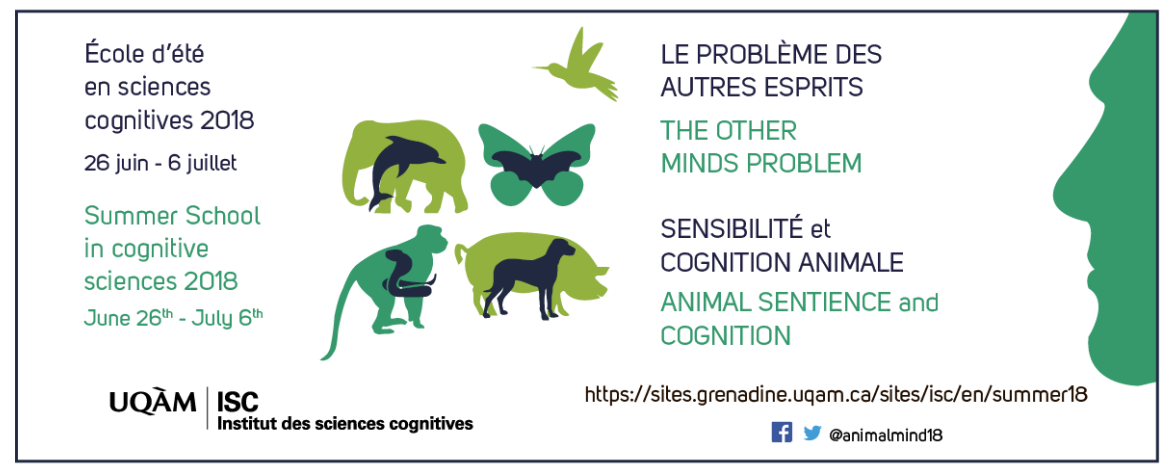

ISC 2018 Summer School in Cognitive Sciences

June 26 - July 6, 2018

Montreal (Canada)

\section{The Other Minds \\ Problem: Animal Sentience and Cognition}

Overview. Since Descartes, philosophers know there is no way to know for sure what — or whether - others feel (not even if they tell you). Science, however, is not about certainty but about probability and evidence. The 7.5 billion individual members of the human species can tell us what they are feeling. But there are 9 million other species on the planet (20 quintillion individuals), from elephants to jellyfish, with which humans share biological and cognitive ancestry, but not one other species can speak: Which of them can feel — and what do they feel? Their human spokespersons - the comparative psychologists, ethologists, evolutionists, and cognitive neurobiologists who are the world's leading experts in "mindreading" other species - will provide a sweeping panorama of what it feels like to be an elephant, ape, whale, cow, pig, dog, chicken, bat, fish, lizard, lobster, snail: This growing body of facts about nonhuman sentience has profound implications not only for our understanding of human cognition, but for our treatment of other sentient species.

Gregory Berns: Decoding the Dog's Mind with Awake Neuroimaging Gordon Burghardt: Probing the Umwelt of Reptiles

Jon Sakata: Audience Effects on Communication Signals

PANEL 1: Reptiles, Birds and Mammals

WORKSHOP 1: Kristin Andrews: The "Other" Problems: Mind,

Behavior, and Agency

Sarah Brosnan: How Do Primates Feel About Their Social Partners?

Alexander Ophir: The Cognitive Ecology of Monogamy

Michael Hendricks: Integrating Action and Perception in a Small

Nervous System

PANEL 2: Primates, Voles and Worms

WORKSHOP 2: Jonathan Birch: Animal Sentience and the

Precautionary Principle

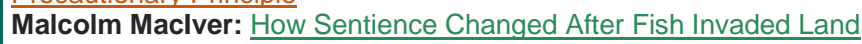
385 Million Years Ago

Sarah Woolley: Neural Mechanisms of Preference in Female Songbird

Simon Reader: Animal Social Learning: Implications for

Understanding Others

PANEL 3: Sea to Land to Air

WORKSHOP 3: Steven M. Wise: Nonhuman Personhood

Tomoko Ohyama: Action Selection in a Small Brain (Drosophila Maggot)

Mike Ryan: "Crazy Love": Nonlinearity and Irrationality in Mate Choice Louis Lefebvre: Animal Innovation: From Ecology to

Neurotransmitters

PANEL 4: Maggots, Frogs and Birds: Flexibility Evolving

SPECIAL EVENT: Mario Cyr: Polar Bears

Colin Chapman: Why Do We Want to Think People Are Different?

Vladimir Pradosudov: Chickadee Spatial Cognition

Jonathan Balcombe: The Sentient World of Fishes

PANEL 5: Similarities and Differences

WORKSHOP 5 (part 1): Gary Comstock: A Cow's Concept of Her Future

WORKSHOP 5 (part 2): Jean-Jacques Kona-Boun: Physical and Mental Risks to Cattle and Horses in Rodeos

\author{
Joshua Plotnik: Thoughtful Trunks: Application of Elephant Cognition \\ for Elephant Conservation \\ Lori Marino: Who Are Dolphins? \\ Larry Young: The Neurobiology of Social Bonding, Empathy and \\ Social Loss in Monogamous Voles \\ Panel 6: Mammals All, Great and Small \\ WORKSHOP 6: Lori Marino: The Inconvenient Truth About Thinking \\ Chickens \\ Andrew Adamatzky: Slime Mould: Cognition Through Computation \\ Frantisek Baluska \& Stefano Mancuso: What a Plant Knows and \\ Perceives \\ Arthur Reber: A Novel Theory of the Origin of Mind: Conversations \\ With a Caterpillar and a Bacterium \\ PANEL 7: Microbes, Molds and Plants \\ WORKSHOP 7: Suzanne Held \& Michael Mendl: Pig Cognition and \\ Why It Matters \\ James Simmons: What Is It Like To Be A Bat? \\ Debbie Kelly: Spatial Cognition in Food-Storing \\ Steve Phelps: Social Cognition Across Species \\ PANEL 8: Social Space \\ WORKSHOP 8: To be announced \\ Lars Chittka: The Mind of the Bee \\ Reuven Dukas: Insect Emotions: Mechanisms and Evolutionary \\ Biology \\ Adam Shriver: Do Human Lesion Studies Tell Us the Cortex is \\ Required for Pain Experiences? \\ PANEL 9: The Invertebrate Mind \\ WORKSHOP 9: Delcianna Winders: Nonhuman Animals in Sport \\ and Entertainment \\ Carel ten Cate: Avian Capacity for Categorization and Abstraction \\ Jennifer Mather: Do Squid Have a Sense of Self? \\ Steve Chang: Neurobiology of Monkeys Thinking About Other \\ Monkeys \\ PANEL 10: Others in Mind \\ WORKSHOP 10: The Legal Status of Sentient Nonhuman Species
}

